\title{
The hazardous terrain of Diabetes mellitus in Nigeria: The time for action is now
}

\author{
Adeleye, J.O.
}

\begin{abstract}
Diabetes mellitus is a chronic metabolic disease characterized by persistent hyperglycemia resulting from absolute or relative deficiencies in insulin secretion and/or action. Diabetes and its complications cause substantial morbidity, disability and premature mortality.

There has been a progressive increase in the prevalence of diabetes mellitus in Nigeria and the burden is expected to increase even further. In view of the increasing burden of diabetes in Nigeria, there is an urgent need to develop and implement an effective and sustainable policy for its prevention and management in the country. If diabetes is not given the attention it deserves now, it could impose an even greater toll on health and socio-economic development in Nigeria and overwhelm an already resource constrained health care system. The time for action is now. Suggested approaches to address the burden of diabetes in Nigeria are discussed in this commentary.
\end{abstract}

Key words: Diabetes, Burden, Nigeria, Action

*Corresponding author

Adeleye, J.O.

ORCID -ID: http://orcid.org/0000-0003-0768-2932

Email address:jokotadea@hotmail.com

Department of Medicine, College of Medicine, University of Ibadan/University College Hospital, Ibadan, Nigeria.

Research Journal of Health Sciences subscribed to terms and conditions of Open Access publication. Articles are distributed under the terms of Creative Commons Licence (CC BY-NC-ND 4.0). (http://creativecommons.org/licences/by-nc-nd/4.0)

http://dx.doi.org/10.4314/rejhs.v9i1.8 


\title{
Le terrain dangereux du diabète sucré au Nigéria: le moment est venu d'agir
}

\author{
Adeleye, J.O.
}

\begin{abstract}
Resume
Le diabète sucré est une maladie métabolique chronique caractérisée par une hyperglycémie persistante résultant de déficiences absolues ou relatives de la sécrétion et / ou de l'action de l'insuline. Le diabète et ses complications entraînent une morbidité, une invalidité et une mortalité prématurée importantes.Il y a eu une augmentation progressive de la prévalence du diabète sucré au Nigéria et le fardeau devrait encore augmenter. Compte tenu de la charge croissante du diabète au Nigéria, il est urgent d'élaborer et de mettre en œuvre une politique efficace et durable pour sa prévention et sa gestion. la maladie dans le pays. Si le diabète ne reçoit pas l'attention qu'il mérite maintenant, il pourrait peser encore plus lourd sur la santé et le développement socio-économique au Nigéria et submerger un système de santé déjà aux ressources limitées. Le temps d'agir est maintenant. Les approches suggérées pour faire face au fardeau du diabète au Nigéria sont discutées dans ce commentaire..
\end{abstract}

Mots clés: Diabète, Fardeau, Nigéria, Action

*Corresponding author

Adeleye, J.O.

ORCID -ID: http://orcid.org/0000-0003-0768-2932

Email address: jokotadea@hotmail.com

Department of Medicine, College of Medicine, University of Ibadan/University College Hospital, Ibadan, Nigeria. 


\section{Introduction}

Diabetes mellitus is a chronic disease requiring lifelong continuing care. The majority of cases of diabetes can be broadly classified into 2 categories: type 1 diabetes and type 2 diabetes $(1,2)$. Type 2 diabetes mellitus (type $2 \mathrm{DM}$ ) accounts for the vast majority (90\%-95\%) of persons living with diabetes (1). Diabetes mellitus is associated with acute and chronic (vascular) complications which reduce quality of life, result in disability and lead to premature mortality $(1,2)$. Diabetes and its complications can result in considerable financial costs to people with diabetes and their families through direct medical costs, loss of work and wages with a significant toll on economic productivity (2).

\section{The Burden of Diabetes}

There has been a progressive increase in the prevalence of diabetes world-wide and it is estimated to increase even further $(3,4)$. The burden of diabetes is also growing in Africa $(3,5)$ and it is estimated that the African region will have the greatest percentage increase (143\%) in the burden of diabetes between 2019 and 2045 (3). Similarly, there has been a progressive increase in the prevalence of diabetes mellitus in Nigeria. Studies have reported prevalence rates of diabetes mellitus ranging between $0.8-4.4 \% \quad(6-8)$ in some rural communities of Nigeria, while the prevalence in urban areas has been reported to range between $4.6-7 \%(9,10)$. A recently published systemic review and meta-analysis of studies on the prevalence of diabetes mellitus amongst Nigerians has reported an overall pooled prevalence of $5.77 \%$ (11). As at 2019,8.2 million Nigerians were estimated to have impaired glucose tolerance, with the number projected to increase to 11.5 million by 2030.(3). This is of great concern, as impaired glucose tolerance is a major risk factor for the future development of type 2 diabetes and cardiovascular disease. As urbanization continues and populations age, diabetes mellitus is therefore set to become an even larger health problem in Nigeria.

Despite the growing evidence of the impact of diabetes mellitus and related noncommunicable diseases in Nigeria, communicable diseases are prioritized over non-communicable diseases (NCDs) (12). This is of great concern, as diabetes mellitus has become an increasingly important cause of morbidity and mortality in Nigeria (1214). Common causes of morbidity and mortality amongst Nigerians with diabetes mellitus include the hyperglycemic emergencies, diabetic foot ulceration and stroke (13-14). Chronic kidney disease (15) and visual loss (16) resulting from diabetes are also increasing amongst the Nigerian populace.

The increasing burden of diabetes mellitus in sub-Saharan Africa in general and Nigeria in particular, is worrisome and it is now a disease of public health significance in Nigeria. The growing burden of diabetes in Nigeria is already exerting a considerable toll on individuals, families, communities and health resources, threatening already vulnerable health systems (12-14). As urbanization continues and populations age, diabetes mellitus is set to become an evenlarger health problem. Diabetes should therefore be considered a disease of public health significance in sub-Saharan Africa in general and Nigeria in particular as it constitutes an increasing threat to individuals, families, the community and the nation, bearing in mind the weak and poorly funded health care systems in these regions.

Consequently, the impending crisis of diabetes mellitus calls for immediate action to address its prevention, diagnosis and management in the most cost-effective manner (17-18).

\section{What should we do at a time like this?}

\section{1) Advocate for increased awareness on diabetes mellitus and the need to improve care for persons with diabetes}

Advocacy, policy and care are essential components in the prevention and control of diabetes. There is need for a strong and continuous campaign to raise awareness 
on diabetes mellitus in Nigeria. Collaborative efforts targeted at advocacy and education by government, policymakers, professional bodies, health care providers, non-governmental organizations, media and the general public on diabetes prevention, healthy living and the needs of persons with diabetes are crucial at a time like this.

In the last decade there has been a robust global response to the increasing burden of NCDs. The United Nations made a political declaration on the prevention and control of NCDs in 2011 (19). The WHO Global Action Plan for the Prevention and Control of NCDs 2013-2020 was also endorsed at the 66th World Health Assembly (20). The global action plan offered a paradigm shift by providing a road map and a menu of policy options for Member States.

The National Strategic Plan of Action on Prevention and Control of NCDs by the Federal Ministry of health, Nigeria was published in September 2015 (21). This document included a strategy for the prevention and control of diabetes mellitus in Nigeria. The intent of this document was to provide government and all relevant stakeholders with a framework for designing and implementing evidence-based strategies and interventions that would address the prevention and control of NCDs in Nigeria.

In August 2019, the Federal Ministry of Health in collaboration with the World Health Organization (WHO) and key stakeholders also launched the "National Multisectoral Action Plan (NNMSAP)" for the Prevention and Control of Noncommunicable Diseases (NCDs) in Nigeria (22). The implementation of this plan was intended to be a collaboration between the Federal Ministry of Health, State Ministries of Health, Primary Health Care development agencies and other key stake holders such as research institutions, industry partners, the media, as well as private and major international agencies in specific areas such as funding, advocacy, resource mobilization and capacity building for the prevention and care of NCDs including diabetes mellitus.

At the moment, it does appear that there is still a tremendous amount of work to be done with regards to implementing the above action plan for the management and prevention of diabetes and related NCDs in Nigeria, especially at primary and secondary health levels of care.

\section{2) Health system reorganization targeted at improving access to and quality of diabetes treatment and care}

Persons with diabetes mellitus require continuing medical care and selfmanagement education to prevent or retard the development and progression of complications $(1,23)$. Provision of effective care for persons living with diabetes requires the presence of trained personnel, access to essential investigations and medications, the use of evidence based protocols for management, appropriate training of health care providers, an effective referral system and the active participation and motivation of the patient $(2,24)$.

WHO has recommended that governments reorient their health systems to include prevention of diabetes and other NCDs in their universal health coverage policies and plans. According to the WHO, "people with diabetes and related NCDs require long-term care that is proactive, patient centered, community based and sustainable" $(2,24)$. Care and management of diabetes should be fully integrated with and reinforce existing health service platforms. It is recommended that such care be delivered by a comprehensive, community-based and primary care led service if it is to be equitable and successful in developing countries $(2,24)$. This would bring prevention and control of diabetes close to where people live and work, thus reducing the burden of the diseases on the populace. Extending and integrating diabetes care into primary and secondary levels of healthcare should therefore be given top priority $(2,24)$. The aim should be to improve access to care and promote an optimal organization and delivery of care for persons living with diabetes, as far as resources allow at all levels of health care via a multisectoral approach $(2,24)$. Unfortunately, at present, basic services for diabetes care and management 
are generally not available in primary health care settings in Nigeria (12). Secondary health centers, particularly those in urban areas do provide some management for persons living with diabetes, but this is often provided by health care providers with limited or no training in diabetes related care often resulting in poor quality of care (12).

Integration and interaction between the various levels of health care is also crucial. A good example of this exists in South Africa, where diabetes care has been devolved as much as possible from the central hospital to primary healthcare (PHC) clinics (27). In these PHC clinics, nurses are the first line of contact and they are able to care for patients using flow charts and algorithms, with referral to higher levels of care when necessary.

\section{3) Training of Health Care Workers}

Knowledge of diabetes and its management has been reported to be poor amongst health-care providers at primary and secondary levels in Nigeria (28). There is also a paucity of high-quality diabetes education and training programmes for healthcare-personnel, especially in rural areas (25). This has been cited by the International Diabetes Federation (IDF) as "a crucial issue impeding the delivery of highquality diabetes education and care." (29). Diabetes education to empower good selfcare is an integral part of the management of patients with diabetes. Thus, the health care provider is required to have the depth of knowledge necessary to teach a patient effectively.

Effective education and training of health care providers in Nigeria to enable them provide good quality diabetes education and care tailored to the milieu of the environment and culture is crucial. Training programmes need to be rolled out to improve knowledge, with appropriately developed materials as guidelines and protocols (25). The WDF funded SIDCAIN project in Ogun and Oyo states involved the training of health care workers at secondary health care levels and has proven that the above is possible in the Nigerian milieu and can be propagated nationwide (28). Noncommunicable disease (NCD) clinics for the care of persons with diabetes and hypertension were also established in all the local governments in Ogun and Oyo state, with the trained health care workers constituting the core of these clinics.

\section{4) Task shifting strategy in Diabetes care}

The development and introduction of community health workers (CHWs) has been proposed as a model for delivering accessible and realistic diabetes care to the rural poor/underserved populations in Africa (30). Task shifting has been defined as "the rational redistribution of tasks among health workforce teams, where tasks are moved where appropriate, from highly qualified health workers, to health workers with shorter training and fewer qualifications in order to make more efficient use of available human resources for health" (31). Nurses are more available in most settings in Africa and in greater number compared with physicians, so empowering the former is a potential solution to the acute shortage of trained health staffs for the control and prevention of chronic diseases in Nigeria (32). Nurse-led diabetes care and education has been successfully implemented in some subSaharan African countries with the use of protocols, and has resulted in positive outcomes in terms of glycemic control (3335). Nurses in Nigeria if given adequate education and training can also play a significant role in the diabetes care team.

Patients with diabetes in rural areas more often than not have to travel to urban areas to access care with the cost of care often beyond their reach. Community health worker interventions have been reported to be a promising strategy for improving diabetes care, among low income or underserved populations (36). They serve in a variety of roles including patient care and education, support for care delivery provided by other health professionals, care coordination and social support (37). In Nigeria, where there is a significant shortage of health care professionals, community 
health workers (CHWs) can help address this challenge in a bid to improve diabetes care for the underserved population of Nigeria. There has been a progressive move in this direction in some sub-Saharan African countries. Task shifting is an attractive strategy to address the shortage of health workforce, but some checks and balances are needed for its safe implementation (32). It should be applied in an organized manner so that the quality of care and patient safety is not compromised $(32,36,37)$. A good community health worker system for diabetes care requires comprehensive training course, with a structured plan of education. It is advised "this be done in a manner, which is understandable, applicable and learnable, given by professionals actively working in the field or a team of mobile professionals employed to educate CHWs on site" $(30,32,36,37)$. Supervision and updating of the training of the CHWs would help to ensure they provide quality service to the populace. The provision of user friendly treatment guidelines and algorithms, supply of testing materials, consumables and essential drugs are essential for delivering acceptable standards of care $(32,36,37)$. Contact with a secondary health care facility is thought to be essential in order that CHWs can refer to a higher level of care where necessary. The proposals made above could be initiated as a pilot programme in 1 or 2 local governments in Nigeria and subsequently extended throughout the state and country if found to be beneficial and costeffective.

\section{5) Quality of care, availability of and access to care}

In a study conducted to assess the quality of care provided at a diabetes outpatient clinic of a tertiary hospital in Nigeria using quality indicators approved by the National Diabetes Quality Improvement Alliance (NDQIA), process measures quality indicators for persons with diabetes in this diabetes clinic were generally unsatisfactory (38). Process measure indicators for which there was no extra charge, such as blood pressure and weight measurement were performed in the vast majority of these patients, but the frequency of measurement of laboratory parameters such as glycated hemoglobin (HbA1c) and lipid profile was poor. The vast majority of Nigerian patients with diabetes largely pay for care "out of pocket". It is estimated that less than $10 \%$ of Nigerians with diabetes are enrolled on the National Health Insurance Scheme (NHIS), with the vast majority of Nigerians paying out of packet for health care services (12). Even where adequate facilities exist for care and management of persons with diabetes in Nigeria, out of pocket expenses hinder access or significantly hinder the delivery of care.

Diabetes and related NCDs continue to place a large financial burden on people in Africa and in Nigeria, as most people pay out of pocket $(12,25,26)$. Achieving universal health coverage enables individuals and communities to have access to health services they require $(2,39)$. This will significantly enable persons with diabetes to access and receive care as at when required. Unfortunately, the process towards the goal of universal health coverage in Nigeria has been painfully slow and needs to be rapidly scaled up (40).

\section{6) Provision of data from high quality diabetes epidemiology research}

Accurate diabetes estimates depend on availability and quality of up-to-date diabetes studies. ${ }^{5}$ The International Diabetes Federation (IDF) recommends strengthening national screening surveys and regular surveillance systems to all countries (3) Investment in research and development is absolutely essential. This should ideally be guided by a national research agenda, mindful of the needs of community and the nation. Accurate and systematic recording, analysis and dissemination of data on the burden of diabetes (e.g., mortality and morbidity), risk factors for/determinants of diabetes and other relevant data amongst Nigerians is fundamental. This is essential for planning, developing and evaluating determinants/risk factors, preventive procedures, public health practices and 
health care services $(25,26)$.

\section{CONCLUSION}

Health decision makers, non-governmental organizations and healthcare professionals in Nigeria must work together in the fight to reduce the burden of diabetes. According to the World Health Organization (WHO), "diabetes mellitus and other NCDs can be largely prevented or the burden significantly reduced with an approach that incorporates evidence based, affordable, cost-effective and population wide interventions" (2). Effectively addressing the danger diabetes portends will require various approaches, alongside integrated multisectoral interventions at primary, secondary and tertiary levels of care (26). The time for action is now!

\section{REFERENCES}

1. American Diabetes Association. Classification and diagnosis of diabetes: Standards of Medical Care in Diabetes 2018. Diabetes Care 2018;41(Suppl. 1): S13-S27

2. World Health Organization. (2016). Global Report on Diabetes. World Health Organization. http://www.who.int/iris/handle/10665/204871. Accessed 25th April 2019.

3. International Diabetes Federation. IDF Diabetes Atlas, 9th edn. Brussels, Belgium; International Diabetes Federation.

4. Saeedi P, Petersohn I, Salpea P, Malanda B, Karuranga S, Unwin N et al, On behalf of the IDF Diabetes Atlas Committee. Global and regional diabetes prevalence estimates for 2019 and projections for 2030 and 2045: Results from the International Diabetes Federation Diabetes Atlas, 9th edition. Diabetes Res Clin Pract 2019 $\mathrm{N}$ o v ; 157 : 107843 . d o i : 10.1016/j.diabres.2019.107843

5. NCD Risk Factor Collaboration (NCD-RisC) Africa Working Group, Trends in obesity and diabetes across Africa from 1980 to 2014: an analysis of pooled population-based studies, International Journal of Epidemiology 2014; 46: 1421-1432, https://doi.org/10.1093/ije/dyx078

6. Sabir AA, Ohwovoriole AE, Isezuo SA, Fasanmade O, Abubakar S, Iwuala S. Type 2 diabetes mellitus and its risk factors among the rural Fulanis of Northern Nigeria, ANN Afr Med. 2013; 12:217-222.

7. Ejim EC1, Okafor CI, Emehel A, Mbah AU, Onyia U, Egwuonwu T, Akabueze J, Onwubere BJ. Prevalence of cardiovascular risk factors in the middle-aged and elderly population of a Nigerian rural community. J Trop Med. 2011; 2011:308687. doi: $10.1155 / 2011 / 308687$.
8. Oladapo OO, Salako L, Sodiq O, Shoyinka K, Adedapo K, Falase AO. A prevalence of cardiometabolic risk factors among a rural Yoruba south-western Nigeria population: a populationbased survey. Cardiovasc J. Afr 2010; 21:26-31.

9. Sabir AA, Isezuo SA, Ohwovoriole AE. Dysglycaemia and its risk factors in an urban Fulani population of northern Nigeria, West Afr J Med. 2011; 30:325-330.

10. Enang OE, Otu AA, Essien OE, Okpara H, Fasanmade OA, Ohwovoriole AE, Searle J. Prevalence of dysglycemia in Calabar: a crosssectional observational study among residents of Calabar, Nigeria. BMJ Open Diabetes Research and Care 2014; 2: e000032.doi:10.1136/bmjdrc2014-000032.

11. Uloko AE, Musa BM, Ramalan MA, Gezawa ID, Puepet FH, Uloko AT, Borodo MM, Sada KB. Prevalence and Risk Factors for Diabetes Mellitus in Nigeria: A Systematic Review and MetaAnalysis. Diabetes Ther. (20 1 8 ). https://doi.org/10.1007/s13300-018-0441-1.

12. Fasanmade OA, Dagogo-Jack S. Diabetes Care in Nigeria. Annals of Global Health 2015; 81: 821829.

13. Chijoke A, Adamu A.N, Makusidi A.M. Mortality patterns among type 2 diabetes

mellitus patients in Ilorin, Nigeria. JEMSDA. 2010; 15:79-82.

14. Ogbera AO, Chinenye A, Onyekwere A, Fasanmade O. Prognostic indices of diabetes mortality. Ethn Dis 2007; 17: 721-725.

15. Adejumo O.A, Okaka EI, Madumezia G, Okuwonu CG, Ojogwu LI. Assessment of some cardiovascular risk factors in predialysis chronic kidney patients in Southern Nigeria. Niger Med J. 2015; 56:394-399.

16. Kyari F, Tafida A, Sivasubramaniam S, Gudlavalleti VS Murthy, Peto T, Gilbert CE, Prevalence and risk factors for diabetes and diabetic retinopathy: results from the Nigeria national blindness and visual impairment survey and The Nigeria National Blindness and Visual Impairment Study Group. BMC Public Health 2014; 14:1299. https://doi.org/10.1186/14712458-14-1299. Accessed: 29th May 2020.

17. Atun R, Gale E.A. The challenge of diabetes in sub-Saharan Africa. The Lancet Diabetes \& Endocrinology 2015; 3:675-677. doi: 10.1016/S2213-8587(15)00236-3.

18. Jaffar S, Gill G. The crisis of diabetes in subSaharan Africa. The Lancet Diabetes \& Endocrinology 2017; 574-575. doi: 10.1016/S2213-8587(17)30219-X.

19. Political Declaration of the High-level Meeting of the General Assembly on the Prevention and Control of Non-communicable Diseases. https://www.who.int/nmh/events/un_ncd_summi t2011/political_declaration_en.pdf?ua $=1$ A d 29th May 2020.

20. Global action plan for the prevention and control of non-communicable diseases 2013-2020. World 
$\mathrm{H}$ e a $1 \mathrm{th} \quad \mathrm{Organ} \mathrm{izat}$ i o $\mathrm{n}$. https://apps.who.int/iris/bitstream/handle/10665/ 94384/9789241506236 eng.pdf; Accessed: 29 May 2020

21. National Strategic Plan of Action on Prevention and Control of Non Communicable Diseases (NCDs), Non-Communicable Disease Control Programme, Federal Ministry of Health Abuja, $\mathrm{N}$ i g e ri a, $\quad \mathrm{M}$ a y 2013. https://extranet.who.int/nutrition/gina/sites/defau lt/files/NGA2013National $\% 20$ Policy $\% 20$ and $\% 2$ 0Plan\%20of\%20Action\%20on\%20NCDs.pdf. Accessed 29 May 2020.

22. First National Multisectoral Action Plan (NNMSAP) for the Prevention and Control of Non-communicable Diseases (NCD) in Nigeria. https:/www.afro.who.int/news/nigeria-fulfilscommitment-launches-plan-prevention-andcontrol-non-communicable-diseases. Accessed May $29^{\text {th }} 2020$.

23. International Diabetes Federation. Recommendations For Managing Type 2 Diabetes In Primary Care, 2017. www.idf.org/managingtype2-diabetes. Accessed 20th May 2018.

24. Implementation tools: Package of Essential Noncommunicable (PEN) Disease Interventions for Primary Health Care in Low-Resource Settings. Geneva: World Health Organization; 2013.

25. Beran D, Yudkin J.S. Diabetes care in sub-Saharan Africa. Lancet 2006; 368:1689-95.

26. Mbanya J.C, Motala A.A, Sobngwi E, Assah F.K, Enoru S.T. Diabetes in sub-Saharan Africa. Lancet 2010; 375:2254-66.

27. Coleman R, Gill G, Wilkinson D. Noncommunicable disease management in a resourcepoor setting: a primary health care model from rural South Africa. Bull World Health Org 1998; 76: 633-640

28. Strategies for Improving Diabetes Care in Nigeria (SIDCAIN) Research Group. Knowledge of diabetes and hypertension care among health care workers in South West Nigeria. Postgrad Med. 2009; 121:173-177.

29. International Diabetes Federation. Consultative section on Diabetes Education 2002:3-12.
30. Price C. Diabetes education at the primary health care level. International Diabetes Digest 1998; 9: 40-41.

31. WHO. Task shifting: rational redistribution of tasks among health workforce teams: global recommendations and guidelines (2007), at http://apps.who. Int/iris/handle/10665/43821.

32. Lekoubou A, Awah P, Fezeu L, Sobngwi E, Kengne AP. Hypertension, Diabetes Mellitus and Task Shifting in Their Management in SubSaharan Africa. Int. J. Environ. Res. Public Health 2010, 7, 353-363; doi:10.3390/ijerph7020353

33. Acheampong JW, Boateng KA, Eghan BA, Story P, Parry EHO, Tomlinson S. The impact of diabetes nurses in the Komfo Anokye Teaching Hospital, Ghana. Diabetes International 2000; 10: 81-83.

34. Gill, GV, Price C, Shandu D, Dedicoat M, Wilkinson D. An effective system of nurse-led diabetes care in rural Africa. Diabet. Med. 2008, 25, 606-611.

35. Kengne AP, Sobngwi E, Fezeu L, Awah, KP, Dongmo S, Mbanya JC. Setting-up nurse-led pilot clinics for the management of non-communicable diseases at primary health care level in resourcelimited settings of Africa. PAMJ. 2009, 3: 10.

36. Shah M, Kaselitz E, Heisler M. The role of Community Health Workers in Diabetes: Update on Current literature. Curr Diab Rep. 2013; 13: 163-171.

37. Norris SL, Chowdhury FM, Van Le K, Horsley T, Brownstein JN, Zhang X, Jack L Jr, Satterfield DW. Effectiveness of community Health workers in the effective care of persons with diabetes, Diabet Med 2006; 23: 544-556

38. Adeleye JO, Kuti MA. Process and outcome measures of quality of care at the diabetes outpatient clinic, University College Hospital, Ibadan. Niger J Clin Pract. 2017; 20: 221-225.

39. https://www. who.int/news-room/factsheets/detail/universal-health-coverage-(uhc). Accessed $22^{\text {nd }}$ January 2021.

40. Okpani AI, Abimbola S. Operationalizing universal health coverage in Nigeria through social health insurance. Nigerian Medical Journal 2015; 56:305-310.

How to cite this article:

Adeleye, O.J. The hazardous terrain of Diabetes mellitus in Nigeria: The time for action is now. Research Journal of Health Science, 2021,9(1): 69-76 